\title{
BM] open A serial qualitative interview study of infant feeding experiences: idealism meets realism
}

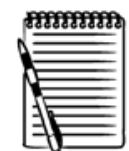

PRESS

RELEASE

To cite: Hoddinott $P$, Craig LCA, Britten J, et al. A serial qualitative interview study of infant feeding experiences: idealism meets realism. BMJ Open 2012;2:e000504. doi:10.1136/

bmjopen-2011-000504

- Prepublication history and additional materials for this paper are available online. To view these files please visit the journal online (http://dx. doi.org/10.1136/ bmjopen-2011-000504).

Received 21 October 2011 Accepted 20 January 2012

This final article is available for use under the terms of the Creative Commons Attribution Non-Commercial 2.0 Licence; see http://bmjopen.bmj.com

${ }^{1}$ Health Services Research Unit, University of Aberdeen, Aberdeen, UK

${ }^{2}$ Public Health Nutrition Research Group, University of Aberdeen, Aberdeen, UK ${ }^{3}$ School of Nursing, Midwifery and Health, University of Stirling, Stirling, UK

Correspondence to Dr Pat Hoddinott; p.hoddinott@abdn.ac.uk

\section{ABSTRACT \\ Objective: To investigate the infant feeding} experiences of women and their significant others from pregnancy until 6 months after birth to establish what would make a difference.

Design: Qualitative serial interview study.

Setting: Two health boards in Scotland.

Participants: 72 of 541 invited pregnant women volunteered. 220 interviews approximately every 4 weeks with 36 women, 26 partners, eight maternal mothers, one sister and two health professionals took place.

Results: The overarching theme was a clash between overt or covert infant feeding idealism and the reality experienced. This is manifest as pivotal points where families perceive that the only solution that will restore family well-being is to stop breast feeding or introduce solids. Immediate family well-being is the overriding goal rather than theoretical longer term health benefits. Feeding education is perceived as unrealistic, overly technical and rules based which can undermine women's confidence. Unanimously families would prefer the balance to shift away from antenatal theory towards more help immediately after birth and at 3-4 months when solids are being considered. Family-orientated interactive discussions are valued above breastfeeding-centred checklist style encounters.

Conclusions: Adopting idealistic global policy goals like exclusive breast feeding until 6 months as individual goals for women is unhelpful. More achievable incremental goals are recommended. Using a proactive family-centred narrative approach to feeding care might enable pivotal points to be anticipated and resolved. More attention to the diverse values, meanings and emotions around infant feeding within families could help to reconcile health ideals with reality.

\section{INTRODUCTION}

The observational evidence for the maternal and infant health benefits of breast feeding in both developing and developed countries is growing. Accordingly, many governments endorse WHO recommendation of exclusive breast feeding, with no other fluids or solids,

\section{ARTICLE SUMMARY}

Article focus

- To investigate the perspectives of women and their wider family and social network on infant feeding from pregnancy until 6 months after birth.

- To ascertain what would make a difference to their experiences of breast feeding and the introduction of other fluids and solids.

- To focus on health inequalities and to understand interactions between women, professionals, organisations and systems to inform policy, practice and the design of complex intervention trials to improve infant feeding outcomes.

\section{Key messages}

- Clashes between overt or covert idealism and realism within and between families and the health service occur at pivotal points particularly in the early weeks after birth and around the introduction of solids.

- At pivotal points, families often perceive the only solution within their control that will restore family well-being is to stop breast feeding or introduce solids or other fluids. Using a familycentred narrative approach could enable pivotal points to be anticipated and resolved.

- Translating global policy goals like exclusive breast feeding until 6 months into practice is unhelpful and achievable incremental goal setting is recommended.

not even water, for 6 months, followed by the appropriate introduction of solids and continued breast feeding for 2 years and beyond. ${ }^{1}$ Yet in many developed countries, rates of any breast feeding let alone exclusive breast feeding are a long way from this ideal. Breastfeeding incidence is increasing, but internationally, the duration and exclusivity of breast feeding seem more resistant to change. $^{2-5}$ Less than $1 \%$ of UK babies were reported to be breastfed exclusively at 6 months in $2005,{ }^{6}$ although the percentage of babies receiving solids at 4 months fell from $85 \%$ in 2000 to $65 \%$ in 2005 . Crosscountry comparisons are problematic due to 


\section{ARTICLE SUMMARY}

Strengths and limitations of this study

- Original interpretation using robust and transparent methods in a relatively large data set of serial interviews about infant feeding, with recruitment of women living in more disadvantaged areas.

- Findings which are relevant to current policy and practice, particularly the Unicef Baby Friendly initiative.

- An explicit aim to elicit the views of women and their significant others to inform future intervention studies, policy and practice.

- Our findings are hypothesis generating rather than hypothesis testing.

- It is uncertain how transferable our data is outside the UK context, particularly to countries where breast feeding prevalence is high.

- Although we targeted more disadvantaged areas for recruitment, our sample was more economically advantaged than we would have liked.

variations in how exclusivity is measured. ${ }^{7}$ However, there are some interesting contrasts, with Canadian data showing an increase in exclusive breast feeding at 6 months from $17.3 \%$ in 2003 to $23.1 \%$ in $2007-2008,{ }^{3}$ but in the USA, rates decreased from $14.1 \%$ in 2006 to $13.3 \%$ in $2010 .^{2}{ }^{8}$ In 2005 , nine of 10 UK women who breastfed for $<6$ weeks reported that they would have liked to have breastfed for longer ${ }^{6}$ and recent qualitative evidence syntheses ${ }^{9-11}$ and survey data ${ }^{12}$ suggest that postnatal infant feeding services are not consistently meeting women's needs.

In the face of these statistics and in an attempt to motivate health service providers and improve outcomes, governments have set less ambitious targets. Increases in breastfeeding initiation in England and Wales from $71 \%$ in 2000 to $82 \%$ in $2010^{4}$ did not meet the 2006 target of increasing breastfeeding initiation by $2 \%$ per year. ${ }^{13}$ In 2008, this target was replaced by a requirement for each primary care trust to report breastfeeding rates at 6-8 weeks and deliver local improvements. ${ }^{14}$ Similarly in the last decade, USA targets for breast feeding at 6 months were not met and have been cut from $50 \%$ to $25 \% .^{2}$ In Scotland, two recent targets have also not yet been met: a 2008 target of $50 \%$ of women breast feeding at $6-8$ weeks and the equally ambitious target of $33 \%$ of women exclusively breast feeding at $6-8$ weeks by $2011 .{ }^{15} \mathrm{~A}$ region in Northern Italy took a different approach and introduced a $0.5 \%$ payment penalty if Health Authorities failed to meet their locally set breastfeeding targets. ${ }^{16}{ }^{17}$ UK governments are increasingly targeting care towards more disadvantaged families ${ }^{18} 19$ as their babies are more likely to be given formula milk and receive solids early. ${ }^{6}$ The implicit assumption is that more individual advice, help and support for these social groups will lead to increased breastfeeding rates and likelihood of targets being met. ${ }^{18}$ However, the jury is still out on the effectiveness of this approach. ${ }^{2021}$
Infant nutrition guidelines ${ }^{19} 22$ aim to help health services meet targets and are informed by evidence syntheses which consistently show that additional lay and professional support, particularly if it is multi-faceted and spans pregnancy and birth, can prolong the duration and exclusivity of breast feeding. ${ }^{23}{ }^{24}$ However, as this evidence comes mostly from the North America, the extent to which it can be generalised across different health systems is unknown. ${ }^{25}$ Infant feeding interventions mostly educate and/or support individual women ${ }^{23} 24$ or train lay supporters and/or health professionals. ${ }^{26}$ They mostly assume a cognitive model of decision making where pros and cons are weighed up and behaviour changes. However, the widely assumed rational approach seldom applies for more disadvantaged social groups ${ }^{27}$ and automatic processes are increasingly recognised as determinants of behaviour. ${ }^{28}$ This suggests that context and experience may be more influential for some than theoretical knowledge, confirming earlier research on infant feeding decision making among early school leavers. ${ }^{29}$ An example of a widely adopted multi-faceted intervention and systems approach is the Unicef Baby Friendly Initiative (BFI), which is endorsed by the National Institute of Health and Clinical Excellence ${ }^{19} 22$ and provides a focus for organisations to achieve an accreditation award. ${ }^{30}$ The BFI combines research evidence and good practice standards, covering all aspects of service provision and care. Implementing the BFI in Belarus was associated with an increase in duration and exclusivity of breast feeding in the first 12 months of life,${ }^{31}$ however in the UK, the BFI is only associated with an increase in breast feeding up to 7 days, and therefore, its impact remains unclear. ${ }^{32}$ Furthermore, despite milk feeding being part of a feeding continuum for infants and parents, the majority of infant feeding interventions in the first 6 months after birth have focused on breast feeding as the outcome rather than the appropriate introduction of solids and other fluids. Goals and recommendations relating to age of introduction of solids have been subject to similar controversy as those relating to breast feeding.

Our aim was to move away from a focus on the individual to investigate wider family and network perspectives on what would make a difference to their experiences of breast feeding and introducing other fluids and solids. Our intention was to focus on health inequalities and to understand interactions between women, professionals, organisations and systems and thus inform the design of complex intervention trials ${ }^{33}$ to improve infant feeding outcomes.

\section{METHODS}

\section{Design, rationale and setting}

This qualitative serial interview study investigates the perspectives of women and their nominated significant others from late pregnancy until 6 months after birth. Serial qualitative interviews allow trust to develop 
between the researcher and participant, allow early questions generated from data analysis to be explored in depth later and can help validate study findings. ${ }^{34}$ Including significant others captures how relationships change over time and enables infant feeding to be understood in a wider socio-cultural context. Our approach is informed by environmental and ecological theory of behavioural change, which understands healthrelated decisions as constantly adapting to changes in the micro, meso and macro context in which the decisions are made. ${ }^{35}$ The study was conducted in two contrasting Scottish Health Boards around 100 miles apart, where maternity units were implementing the BFI. Two qualitative researchers were based at each site. The research team brought together considerable infant feeding research experience from different backgrounds: nutrition, the voluntary sector, social policy, midwifery and general practice. Conducting qualitative research with a multidisciplinary team can help challenge researcher assumptions and biases, which is important when one of the aims is to develop theoretically informed interventions to test in trials.

\section{Definitions}

Breastfeeding initiation refers to the baby receiving any breast milk, even if only once. Exclusive breast feeding is defined as the infant receiving only breast milk since birth with no other liquids or solids with the exception of drops or syrups consisting of vitamins, mineral supplements or medicines. ${ }^{36}$ Introduction of solids is defined as the first ever solid food offered to and taken by the baby, even if it is only a small amount. Pregnant women recruited to the study were considered as the index cases, and relationships are described in relation to them. We define significant other(s) as the person(s) identified by the woman who has the strongest influence on feeding decisions, regardless of the direction of influence (either for or against the decision).

\section{Recruitment and sampling strategy}

Maternity unit databases were used to identify 459 (site 1) and 533 (site 2) women due to give birth between September and October 2009. As mothers living in disadvantaged areas are less likely to breast feed and to participate in research, ${ }^{6}$ we invited all women living in the three more deprived postcode quintiles of the Scottish Index of Multiple Deprivation (SIMD) ${ }^{37}$ $(n=420)$ and a smaller sample of women living in the two more advantaged SIMD quintile areas $(n=121)$. In more advantaged areas, we recruited families where the woman or her partner had a low age of leaving full-time education, a non-professional occupation, or were immigrants to the UK which may be a disadvantage, particularly around the time of childbirth. The research commissioning brief was to aim to recruit over $75 \%$ of participants from the three more disadvantaged SIMD quintiles and select women with diverse characteristics who intended to breast feed or who had breastfed a previous baby. Invitation packs included an introduc- tory letter on Maternity Unit-headed paper signed by a lead health professional, an information leaflet and a short opt-in characteristics questionnaire (S1) with a free post envelope to inform purposive sampling. Of 541 invitation letters sent out 4-8 weeks prior to a woman's estimated date of delivery, $72(13 \%)$ women volunteered to participate and provided socio-demographic data. Using a sampling frame, we selected 18 women from each site for the characteristics listed in table 1 . The index women were asked to identify significant others (partners, family, friends and health professionals) throughout the study and the researcher negotiated informed consent to interview a diverse range of information rich significant others at different points.

\section{Data collection}

Our aim was to interview women and their significant others every 4 weeks, at a time and place to suit them. We negotiated frequency of contact, being sensitive to the emotional and physical impact the arrival of a new baby can have on a family. Face-to-face interviews took place at

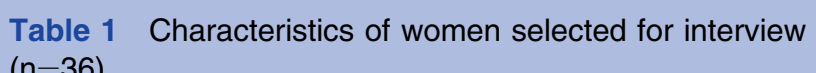
$(n=36)$

Site 1 participants Site 2 participants $(n=18) \quad(n=18)$

$\begin{array}{ccr}\text { Age (years) } & \\ \leq 20 & 0 & 3 \\ 21-30 & 4 & 4 \\ 31-40 & 11 & 11 \\ \leq 40 & 3 & 0 \\ \text { Age at leaving } & \text { full-time education (years) } \\ \leq 16 & 1 & 3 \\ 17 & 1 & 5 \\ 18 & 3 & 1 \\ \geq 19 & 13 & 9 \\ \text { Occupational classification* } & \\ 1-3 & 10 & 6 \\ 4-6 & 5 & 8 \\ 7-9 & 2 & 3 \\ \text { Not employed } & 1 & 1 \\ \text { Parity } & & \\ 0 & 9 & 10 \\ \geq 1 & 9 & 8 \\ \text { SIMD } & & 13 \\ 1-3 & 13 & 5 \\ 4-5 & 5 & \end{array}$

*Standard Occupational Classification (SOC 2000) taken from the 2000 Census (available at: http://www.ons.gov.uk/ons/guidemethod/classifications/archived-standard-classifications/standardoccupational-classification-2000/index.html): 1. Managers and senior officials, 2. Professional occupations, 3. Associate professional and technical occupations, 4. Administrative and secretarial occupation, 5. Skilled trade occupations, 6. Personal service occupations, 7 . Sales and customer service occupations, 8. Process and plant and machine operatives and 9. Elementary occupations.

†Scottish Index of Multiple Deprivation 2009: http://www.scotland. gov.uk/Publications/2009/10/28104046/0. SIMD 1 is the most deprived quintile. SIMD 5 is the least deprived quintile. SIMD, Scottish Index of Multiple Deprivation. 
home during pregnancy, within 4 weeks of birth and at 6 months, with shorter, mostly telephone, interviews $(0-5)$ in between. Two participants preferred face-toface interviews throughout as English was not their first language. Prior to contact after birth, we consulted midwives who accessed NHS records to ensure a safe delivery had occurred. A website discussion forum was available throughout the study. This complemented interview data and enabled contributions from volunteer parents who had not been selected to participate. However, only 25 people registered; one was a woman participating in the study (4 posts) and two of the 72 volunteers who were not selected for the study posted twice each. The research team posted five questions to stimulate discussion (S2).

Interviews were semistructured, using topic guides that were modified over the course of the study to probe emerging themes in more depth and to search for disconfirming data (S3). At the end of each interview, researchers collected structured information about significant others influential since the last interview (age, relationship, distance from the family and feeding experience). In particular, any inconsistencies or changes in the person(s) nominated as significant at different time points could be explored. Similarly, researchers collected structured data at each time point about breastfeeding duration, exclusivity and introduction of non-milk liquids and solids, based on the Office for National Statistics five yearly UK survey questions. ${ }^{6}$

Prior to the final interview, the research team constructed seven vignettes describing a range of health or community services to help with infant feeding informed by the emergent data analysis and the research evidence (S3). The vignettes were multi-component and designed as research tools to assist the development of interventions for future research. They were given to participants to read and comment on at the final 6-month interview. Details are provided in the full report. ${ }^{38}$

\section{Data analysis}

Data collection and analysis progressed iteratively, with the four authors involved in listening to interview recordings, reading verbatim transcripts, identifying and interpreting themes and agreeing modifications to topic guides according to the emerging analysis. All interview transcripts were entered as data units onto FrameWork software. ${ }^{39}$ FrameWork is a rigorous systematic data management tool, which allows original data and researcher interpretations to be transparently documented and maintains the important direct link between coded themes, interpretations and the original interview data. ${ }^{40}$ The four researchers independently constructed a thematic index by reading a sample of six information rich and diverse transcripts of antenatal and first postnatal interviews and then reached consensus through discussion. A further six interviews were selected in a similar manner to add to the index to cover the introduction of solids. A final thematic index for the antenatal and early postnatal interviews was agreed approximately half way through data collection when these interviews were complete and finalised for the introduction of solids towards the end of data collection. The index was used to organise, label and summarise data, which facilitated the construction of different charts, with cases (rows) and themes (columns). Charts compared summarised theme data for couples with differing attributes, for example, primiparous compared with multiparous women, early cessation of breast feeding compared with late, early introduction of solids compared with late and differences in the level of partner or significant other involvement with infant feeding. Analysis proceeded by researchers listening to interviews, reading transcripts, keeping reflective diaries, identifying interpretive themes, discussing them, generating research questions, creating different FrameWork charts to explore patterns and to search for disconfirming data. Towards the end of our analysis, we returned to the web discussion forum data to search for any disconfirming data and no such data were found.

\section{RESULTS}

A total of 220 recorded individual or pair interviews took place with 36 women (table 1) and 37 significant others (26 partners, 8 maternal mothers, 1 sister and 2 health professionals) between two and eight times (table 2). All women intended to breast feed except one who had breastfed a previous baby but intended to formula feed on this occasion. Two families withdrew from the study after the first postnatal interview. Both had stopped breast feeding in the first week. The remaining 34 families were each interviewed from the last trimester of pregnancy until 6 months after birth.

The meanings attributed to infant feeding and the competing values which influence feeding decisions differ considerably both within and between families. Figure 1 summarises the overarching theme emerging from our data as a mismatch between idealism and realism. Those involved in infant feeding-families, their social networks and the health service-hold different explicit or implicit philosophical positions of idealism or realism about infant feeding. By idealism, we imply the construct of ideal feeding based on the research evidence that optimises child and maternal

Table 2 Interview frequency

\begin{tabular}{ll}
$\begin{array}{l}\text { Number of index } \\
\text { cases (women), } \\
\mathbf{n = 3 6}\end{array}$ & $\begin{array}{l}\text { Number of interviews } \\
\text { where a significant } \\
\text { other was present }\end{array}$ \\
\hline 2 & 3 \\
- & - \\
1 & 2 \\
6 & 8 \\
15 & 27 \\
6 & 7 \\
6 & 15 \\
\hline
\end{tabular}


health: currently exclusive breast feeding for 6 months and continued breast feeding for 2 years and beyond. ${ }^{1}$ Idealists are guided by high moral or intellectual feeding values and adhere to guidelines espousing optimum infant feeding. By realism, we imply that women, families and health professionals accept the situation as it is and are prepared to deal with it practically or pragmatically. For infant feeding in the real world, there are multiple individual or family values that compete with the optimum health ideal. In the top half of figure 1, we set out how accounts of infant feeding and wider sociocultural values of women and families in our study fit with the overarching theme of idealism meeting realism. In the bottom left quadrant of figure 1, the ideal position of health service providers is derived from current health service guidance. ${ }^{19} 223041$ In the bottom right quadrant, we illustrate how women and families in our study perceive the reality of health service care. We describe how the mismatch and conflict between idealism and realism can cause tensions within families and in the professional-family relationship and how families detect these tensions among health professionals. Importantly, philosophical positions influence how health professionals communicate with parents, including how research evidence is translated visually and verbally. Our analysis builds on earlier qualitative research, particularly evidence syntheses ${ }^{9} 10$ which we reference alongside our findings. The analysis is
Figure 1 Idealism and realism: mismatch within and between families and health services.

\section{Idealism - women and family values \\ Exclusive breastfeeding is the ideal for \\ health and this determines feeding behaviour \\ Breastfeeding is the focus of the first 6 months, with other activities taking second place \\ Intensive mothering with demand feeding. \\ Partners and families supportive in all other aspects of baby care \\ Prepared to persevere however difficult it is and put breastfeeding first \\ Expressing milk allows others to feed or gives mothers baby free time \\ Breastfeeding in public is protected by law in some countries which will empower women Baby behavioural cues before 6 months can be resolved without giving solids}

Idealism - health service ${ }^{19,22,30,41}$

All health service staff fully support exclusive breastfeeding to 6 months to maximise health benefits

All health service staff are trained in core breastfeeding education and support skills

More antenatal preparation and education will result in better outcomes. A rational, cognitive, planned model of behaviour prevails Discussing difficult breastfeeding experiences will put women off

With correct technique breastfeeding will be painless and problem free.

Staff have sufficient time to sit with mothers during breastfeeds and provide help until breastfeeding is established

The transition between hospital and home is smooth with good communication between staff

Proactive care improves feeding outcomes

Rules work. Compliance

Breastfeeding centred checklists improve quality of care
Realism - women and family values

A happy mother, baby and family are the ideal and feeding behaviour is determined by a complex balance of factors

Breastfeeding is one of many competing activities, agendas and values

Sharing responsibility for feeding allows partners, grandparents and others a unique bonding opportunity

Immediate gains of stopping (pain, anxiety, time, sleep) outweigh the delayed rewards of breastfeeding Expressing milk can be difficult, distasteful and as time consuming as breastfeeding

Breastfeeding in public can be difficult and not widely accepted, even if legal

Giving solids has multiple meanings and delaying is counter-intuitive

\section{Realism - health service}

Not all health professionals are fully supportive of exclusive breastfeeding to 6 months. The all or nothing, breast or bottle culture is unpopular Not all staff have the necessary skills and breastfeeding care is highly variable and determined to some extent by luck.

Help to learn breastfeeding after birth is the priority compared to antenatal preparation.

Antenatal care paints an unrealistic picture

Pain and distress are complex emotional, somatic and cultural phenomena, which are seldom resolved by a technical approach alone. Reassurance and confidence building are crucial

Staff cannot offer the support that some women require due to staff shortages and competing demands on time. Sitting through a breastfeed is crucial for confidence building and problem prevention

Care is fragmented between hospital and home, and at day 10-14 between midwife and health visitor

Reactive care when problems are established. Pivotal points occur where feeding plans change rapidly to improve wellbeing

Resistance to rules is common. Deviance Family centred care and listening to experiences is valued 


\section{Box 1 Idealism meets realism before birth}

Partner: [about his sister and her children] it was what was better for both her and the little ones [changing from breast to bottle feeding], because she was getting all up to high doe because she was like "oh it's not working, baby's crying all the time, how am I going to cope with this?" and that sort of thing. We're sort of the same, if it's not working we'll switch. (ID 1044. Antenatal interview)

Woman: I think a reality check actually would be good, because they make it sound so easy, you know, it's like if you just take the baby, you're going to latch it on and it's all going to be plain sailing.... you might be lucky and it might work like that, but you might be the complete opposite. (ID 1010. Antenatal interview)

Partner: Because it's so...you know, breastfeeding centric absolutely everything is, some of it you get wary after a while and go "yeah, yeah, we know, yeah okay, we've heard all that before, so what?" (ID 1173. Antenatal interview)

Woman: The class on breastfeeding, the midwife or health visitor that did it brought out a doll and, you know, it was like something you would've done at playschool, it was quite kind of...you know, made it seem.... I don't know what the word is I'm looking for [laugh] but it wasn't practical, it wasn't kind of realistic. (ID 1040. Antenatal interview)

Partner: If you had mums with babies coming along (to classes before birth) l'd be interested to see where difficulties lay so that I could be there to support and say, "well that's kind of normal" and "d'you remember that woman had that particular issue for a couple of months but then it kind of came good in the end?", kind of thing. (ID 2057. Interview 24+ weeks after birth: breastfeeding, with solids introduced $<16$ weeks but no formula)

Woman: When I asked about expressing it was all very much about hand expressing, which I'm not particularly.... I was more trying to find out about different pumps that are available and that kind of thing. I don't think my question really got answered, did it? (ID 2039. Antenatal interview)

supported by quotations in boxes 1-4 which provide participant ID numbers to enable linkage to more detailed contextual data (socio-demographic characteristics, feeding patterns and significant other relationships) in the full report. ${ }^{38}$ We consider parents' perspectives on how the health service ideal of exclusive breast feeding for 6 months is reconciled with other values throughout the feeding journey and what would make a difference to improve their feeding experiences (box 5).

\section{Pregnancy: rosy pictures and the word on the street}

In pregnancy, many women and their significant others anticipate breastfeeding difficulties and failure, describing scenarios where they would behave differently from their own ideals and those of the health service. Parents hedge their feeding outcomes saying they will try breast feeding and decide from day to day rather than aim for the 6-month goal stated in health service information. New parents do not want to set themselves up to fail, and the expectation-reality gap in women's breastfeeding experiences has been widely documented. ${ }^{10}$ Frustration with this gap is particularly strongly expressed by partners, who comment that antenatal

\section{Box 2 Care after birth}

Woman: [describing qualities of the ideal helper] Patience...tolerance...listening, listening to you...showing you without force...someone that can focus all their attention on you and the baby and the task at hand. (ID 1210. Interview 24 weeks after birth: breastfeeding, with formula introduced at 1 week and solids at 21-24 weeks)

Woman: I asked each time I went to feed her, I buzzed the buzzer to get help. Like they didn't come and offer help, I had to ask for it. So that would be...

Partner: Yeah someone a bit more timid or shy...

Woman: Might not...

Partner: I don't want to bother them, I'll just persevere. Or I don't want to bother them, I'll just give up. (ID 1033. Interview 24 weeks after birth: breastfeeding, with formula introduced at 13-16 weeks and solids at $17-20$ weeks)

Woman: One of the midwives suggested that we give her a bottle and then I could go back to breastfeeding, once l'd had a rest..which was my intention until another midwife told me that I couldn't do that... once she'd been on the bottle then it was best to keep her on the bottle. And she was quite firm to the extent that it was quite unpleasant. (ID 2181. Interview 2 weeks after birth: formula feeding, introduced at 1 week, breastfeeding stopped at 1 week)

Woman: We were struggling with the feeding and I could've done with that additional support right at the beginning, but because of communication not being as good as it should've been, there was that four days that we went without anybody coming round. (ID 1057. Interview 13 weeks after birth: formula feeding; formula introduced at 1 week, breastfeeding stopped 9-12 weeks)

Woman: I must say that what I have had is what I would expect to have in an ideal world! I don't think I would've asked for any more than I got. Because every step that I needed explaining or needed help I always got it. For me it's been a ten out of ten experience, except for the pains [laugh]. (ID 1148. Interview 3 weeks after birth: exclusive breastfeeding)

Woman: The way it's kind of promoted sometimes, it's a lovely bonding experience and when you come home, then you feel guilty yourself because you think, well I'm not having this bonding and lovely experience, I'm having, you know, a kind of hard sore experience. (ID 2103. Interview 3 weeks after birth: breastfeeding, with formula introduced at 3 weeks)

information for breast feeding did not prepare them well for reality. Antenatal breastfeeding preparation 'makes it sound so easy' and fails to acknowledge the more negative word on the street. Most parents prefer to hear about a wide range of positive and negative feeding experiences from recent parents, including those who 'break the rules', whereas such parents seem less likely to be selected by health professionals as role models in antenatal education sessions. Some parents report feeling 'pressured' to breast feed and in extreme cases view breastfeeding promotion as 'propaganda' and suggest that the 'breast is best message' has been overdone, confirming earlier research. ${ }^{42}$ 


\section{Goals: future health versus current well-being}

Woman: I think probably at some point in the middle of the night, tearing your hair out, I thought...considered it, but then...well, I kind of think as well l've got this far so l'm not going to start giving him formula now. (ID1108. Interview 24 weeks after birth: breastfeeding, with solids introduced at 24 weeks, formula not introduced)

Partner: it's [breast milk] better for your wean isn't it? It's all natural stuff, I don't like chemicals, l'm not keen on bottles at all. (ID 2037. Interview 24 weeks after birth: formula feeding, introduced at 9-12 weeks, breastfeeding stopped and solids introduced at 20-24 weeks)

Partner: Well, that's another thing, they say that if you breastfeed that your child is in sort of a lower category of being quite obese. Well, I don't know if I agree with that, because my son is quite big and he was breastfed for 6 month and, I don't know, I don't think he eats...lots of sweets or things like that, so I don't know if I agree with that at all going by him. But yet my daughter's not big, so I don't know if I agree with that or what. (ID1208. Antenatal interview)

Woman: I did feel a bit guilty at first [about stopping breastfeeding]. But then I thought well he wasn't settling and he needs to make sure he's getting fed and l've obviously got to look after myself as well to be able to look after him. (ID 2255. Interview 3 weeks after birth: formula feeding, introduced at 1 week, breastfeeding stopped at 1 week)

\section{Family bonds and intensive mothering}

Partner: For the wean's sake, breastfeeding's best, but for the woman and wean's sake, or the family and the wean's sake, breastfeeding might not be best. (ID 2287. Interview 24 weeks after birth: formula feeding, introduced at 3-4 weeks, breastfeeding stopped at 7-8 weeks, solids introduced at $<16$ weeks)

Partner: For the first few months, all it's doing is waking up, smiling, I want fed now, right I need changed now, and it's effectively that, that's the scenario. So not being involved in doing the nice bit, but doing the majority of the nasty bit, you know, sort of thinking, who's getting the better deal here? (ID 2061. Interview 24 weeks after birth: formula feeding, introduced at 1 week, breastfeeding stopped at 5-6 weeks, solids introduced at $17-20$ weeks)

Woman: He [husband] really enjoys it actually, and I think he's really delighted that [baby] will finally take a bottle from him and, you know, that's kind of their time to sit and chill,... it's really nice actually to see that. I think [husband] feels more connected as well, just being able to do that. (ID 2192. Interview 19 weeks after birth: breastfeeding, with formula introduced at 5-6 weeks)

Woman: It all seems to be, "don't ever do anything that would interfere with breastfeeding", it's all got to be very purist which is fine, but it just doesn't fit in with the rest of your life and I think in a way people just give up because it's too difficult. (ID 1075. Interview 24+ weeks after birth: breastfeeding, with formula introduced at 2 weeks and solids at 21-24 weeks)

Woman: I do think when you've had babies that they [partners] do feel a bit pushed out to be honest. And the kids are my number one, so he's just got to get on with that. (ID 2056. Interview 13 weeks after birth: exclusive breastfeeding)

\section{Time values and strategies}

Woman: He's waking up usually at around 5.30 and by the time I have fed and changed and burped and what have you, [partner] takes over which gives me time to go for a run in the morning so that's really good, so that gives me a bit of "me time". (ID 1056 . Interview 12 weeks after birth: exclusive breastfeeding)

Woman: So he sort of tends to just suckle as often as he can then, but during the day...I only maybe manage to get a couple of hours at the most [laugh]. ...But it's fine, I'm not feeling...I feel really good this time, I don't feel drained physically or anything at all, I feel fine. (ID 2169. Interview 9 weeks after birth: exclusive breastfeeding)

Woman: I have gone back to the gym and done a couple of classes there and his dad looked after him. He's not taken any expressed milk yet, he's not taken to the bottle, but we've only really tried that a couple of times. (ID 1094. Interview 11 weeks after birth: breastfeeding, with formula introduced at $7-8$ weeks)

Breastfeeding education classes or workshops which intensively teach positioning and attachment prior to birth, assisted by videos, dolls and knitted breasts are viewed negatively by many as 'school-like' and 'patronising'. Overly scientific information about anatomy, physiology and the constituents of breast milk is seldom appreciated, as described by others. ${ }^{10}$ A strongly stated preference is to learn about positioning a baby at the breast immediately after birth, with skilled patient and timely help. Messages are perceived as 'breastfeeding centric', presenting breast or bottle as a dichotomy 'you can't do both'. The provision of separate antenatal breastfeeding preparation classes rather than general feeding classes assumes an ideal of fixed early rational decision making and can infer an 'all or nothing' rather than a 'try it and see ${ }^{, 42}$ breastfeeding culture. Many women prefer not to be separated according to feeding intention and welcome open discussions about both formula and breast milk to help them to reconcile health service information with the word on the street. They want to discuss what breast feeding feels like, how it will fit into family life, the practicalities of expressing, what 


\section{Box 3 Continued}

\section{Rules and being a 'good' parent}

Woman: My mum kept saying “it's just trial and error, there's no right and there's no wrong....", because l'm quite bad for getting a bit...even now l'll still sometimes be "oh it's all going wrong" and get over anxious and kind of like "oh, not doing it right and she's not getting what she needs." (ID 1167. Interview 24+ weeks after birth: formula feeding, introduced at 1 week, breastfeeding stopped 3-4 weeks, solids introduced at 24 weeks+)

Woman: one of the midwives I spoke to, she was like "and have you thought about breastfeeding?", I was like "yeah l'm going to try", and she was like "well you know that it's on demand and you can't use bottles and you can't do this and you can't do that, and it's for 6 months and you have to like...", basically you are attached to this baby for 6 months, and she made it seem quite, negative, almost. (ID 2003. Antenatal interview)

Partner: We feel that we've done the right thing [giving solids], but there was not...

Woman: It was a hard decision for us, wasn't it?

Partner: Aye, it was a hard decision because we were going against..

Woman: The rules, if you like...

Partner: The rules, we were breaking the rules. (ID 2294. Interview 24+ weeks after birth: formula feeding, introduced at 1 week, breastfeeding stopped at 21-24 weeks, solids introduced at 16 weeks)

Woman: I kind of got a bit of...not grief, but kind of...like negative tension if you want, for wanting to put him on solids at 17 weeks...and I think if you're breastfeeding they want you to breastfeed for longer because obviously they've managed to get you to breastfeed and it's great and they want you to keep going as long as you can. (ID 2128. Interview 24 weeks after birth: breastfeeding, formula introduced at 1 week and solids at 17-20 weeks)

Woman: Well they've [health visitors] obviously got to follow the regulations about the WHO says this and that and the other. But at the end of the day, my opinion was, as his mum, it was my decision. (ID 1226. Interview 24 weeks after birth: formula feeding, introduced at 2 weeks, breastfeeding stopped and solids introduced at $17-20$ weeks

health service help will realistically be available, return to work and feeding in public. Families report that health professionals vary in the extent to which they take a realist rather than an idealist approach to feeding education, with the former rarely encountered but highly valued. Voluntary sector groups and helplines were infrequently mentioned by participants in our study.

What would make a difference? Skilled facilitation of interactive discussions with individuals, families or groups regardless of feeding intention, which cover the practical and emotional realities of breast and formula feeding and involve parents who have had feeding difficulties and not always lived up to ideals.

\section{Care after the birth}

Although some women are happy with the breast feeding help available on postnatal wards, for most there is a large gap between antenatal ideals or expectations and the reality, confirming international qualitative research synthesis. ${ }^{10}$ Women value proactive help that reassures and builds confidence, continuity of care and staff who help them to latch their baby on themselves. Families describe some healthcare professionals as lacking good communication skills and breastfeeding expertise and, above all, staff were seen to be 'rushed off their feet', leading women to feel 'really bad' about asking for help, and feeling a 'burden rather than a priority'. Occasionally, staff encourage longer hospital stays to establish breast feeding with the implied assumption that hospital care will be better than community care, although evidence does not support this. ${ }^{23}$ Mothers are often distressed by the hospital environment and perceive that they will feel more relaxed and better able to breast feed at home. Early discharge from hospital was a primary goal for some women above breast feeding and it could be the trigger for introducing formula milk to expedite discharge. Women particularly value a member of staff sitting through a feed to provide reassurance that she is 'doing it right'.

What would make a difference? Participants unanimously prioritise the period immediately after rather than before the birth for resources to help women breast feed. Women want someone sitting through feeds to help with breast feeding who increases their confidence.

\section{Goals: future health versus current well-being}

New parents are aware that exclusive breast feeding and delaying the introduction of solids until 6 months are promoted by the health service because of health benefits and many are keen to 'give it a go', confirming earlier research. ${ }^{42}$ Participants' beliefs and opinions about these recommendations vary over the infant feeding journey both within and between families. At one extreme, some parents believe in the recommendations and persevere with exclusive breast feeding - the ease of this depending largely on personal qualities like self-confidence, determination and the 
Woman: I could feel myself welling up because I had my heart set on getting out [of hospital] that day...that's why I said we'd go on to the formula. (ID 2203. Interview 3 weeks after birth: formula feeding, introduced at 1 week, breastfeeding stopped at 1 week)

Woman: I think if it hadn't been for that explanation [from the health visitor], I may well have sort of said, "well I've tried my best, I'm giving up." So I'm glad I didn't, and I didn't because of the health visitor, because she was so reassuring.

Partner: Aye. Because we were getting to the stage where we were...because at the end of the day, all what you'd like to do for her [the baby], the number one priority is she's getting food, getting enough goodness in her, irrespective of where it comes from. (ID 2294 . Interview 2 weeks after birth: breastfeeding, with formula introduced at 1 week)

Woman: That first weekend we gave him a bottle. "That's fine"..., "we call that a crisis bottle," she [health visitor] went, "and there's nothing wrong with that. If it works for you, that's fine, but one bottle a day is not going to do any harm," so if anything she was a bit more encouraging. (ID 2003. Interview 3 weeks after birth: breastfeeding, with formula introduced at 1 week)

Woman: She was wanting fed like almost every hour on the hour, and-with me having [son] and her dad being, runs about a lot, so I was mainly being home by myself and I found it difficult to try and feed her and deal with him as well...and I got to a point I just couldn't cope any more, I was too tired, just wanted to sleep all the time. I thought, "No, can't do this, need to stop." (ID 2287. Interview 12 weeks after birth: formula feeding, introduced at 3-4 weeks, breastfeeding stopped at 7-8 weeks)

Woman: I'd said that I was sort of persevering with it, and she [community midwife] said "try this, try the next thing", but they didn't really sort of offer to show me. I just said that I was topping him up with bottles and I was thinking that it wasn't really working very well, but l'd kind of persevered with it,...but then it was too much. (ID 2255. Interview 3 weeks after birth: formula feeding, introduced at 1 week, breastfeeding stopped at 1 week)

Woman: He was waking every kind of hour and a half/two hours wanting to feed, so I tried him on the solids after speaking to the health visitor. I just would like to sleep and I just don't know why he's not sleeping at night time, so I just have to see if the food will help. (ID 2295. Interview 19 weeks after birth: breastfeeding, with formula introduced $5-6$ weeks and solids $<16$ weeks)

Woman: Kind of a joint decision with the doctor because he'd got to four weeks and he still really hadn't put on any weight, so it was really his health was more important I think rather than fully breastfeeding. (ID1010. Interview 8 wks after birth: breastfeeding, formula introduced at 5-6 weeks)

Woman: After a second bout of mastitis caused me difficulties in finding time to express during the day when my husband had returned to work, I decided effectively last Sunday to stop even trying, and just to focus on the formula feeding. I think, while there's still a part of me that's upset about it, I think generally speaking it's been a relief because l've been able to focus much more on the baby. (ID1173 Interview 6 wks after birth: formula feeding, introduced at 1 week, breastfeeding stopped at 3-4 weeks)

availability of support. For some, the strongest motivator is to avoid a specific health outcome like food allergy or eczema, particularly in families with a history of the condition. For others, the value of 'nature' is paramount, with a desire to avoid formula milk and commercial baby foods, which are seen as artificial, processed and linked to future adverse health outcomes. At the other extreme, some families express doubt about the causal relationship between exclusive breast feeding with introduction of solids at 6 months and longer term health outcomes, particularly obesity. There is an awareness of mixed messages from health professionals about the exact timing of introducing solids, contributing to this doubt. Later childhood sedentary lifestyles and consumption of 'junk food' are perceived as stronger determinants of future health, a view expressed particularly by men. The health consequences of not exclusively breast feeding for 6 months are not readily visible or tangible, and parents who were formula milk fed perceive themselves to be as healthy as others who were breastfed. As in earlier longitudinal qualitative research, narratives describe generations of families given formula milk or solids from 3 months, with no evidence of harm and these accounts are employed to counter any implications of being a 'bad mother' or putting a child at risk. ${ }^{43}$ For all families, current emotional and physical well-being is paramount. But those who are more sceptical about or do not prioritise health recommendations introduce formula milk or solids more readily when feeding difficulties arise, expecting immediate benefits, such as reduced breast pain, more sleep or a contented baby who is gaining weight and resolution of anxiety. Longer term future health benefits are not considered, and the priority is to 'make sure he's getting enough to eat' now, 'regardless of where it comes from'.

What would make a difference? Health professional-family communication about infant feeding would benefit from a move away from checklists and instead ask open questions about experiences, values, priorities and goals with discussion about how feeding will fit into family life. This could reduce the mismatch between ideals, expectations and reality and would allow infant feeding care to be tailored to the family.

\section{Family bonds and intensive mothering}

The hopes and fears of the immediate family and its social network are raised by the arrival of a new baby. 


\section{Box 5 Feeding care: what would make a difference?}

- Prioritise the immediate period after birth for resources to help women to breast feed and 3-4 months after birth for the introduction of solids.

- Provide opportunities for realistic interactive discussions with appropriately skilled healthcare providers and peers before and after birth with the option to include significant others.

- Offer proactive rather than reactive care and anticipate those at risk of changing feeding behaviour at pivotal points.

- Set realistic rather than idealistic goals, at individual, local and national levels.

- Pay more attention to emotional issues than the technicalities of breast feeding by communicating in a narrative style which is woman/family-centred and sitting with women through feeds to build confidence and self-efficacy.

- Use open questions rather than a checklist approach and acknowledge that there are many ways to feed a baby safely.

- Consider organisational systems and structures that would provide continuity of highly skilled feeding care from pregnancy through infancy.

The overriding goal for new parents is emotional and physical well-being, so that the important social ritual of introducing the new baby to the social network is a joyful and fulfilling experience for all, with minimal anxiety and tension. Scenarios of changing feeding behaviour to prioritise family well-being over health values are described, for example, not wanting to 'shun to the side' a 6-year-old daughter who is 'desperate to help' by giving a bottle. Breast feeding is widely promoted as a way for mothers to bond with their babies, leading to anxiety that partners, grandparents or older children will not bond with the baby unless they are actively involved in giving feeds. For some mothers and significant others, actively feeding the baby by bottle or spoon has a higher value than all other baby care tasks and is 'therapeutic' and 'relaxing'. Women are keen to express breast milk as soon as possible to enable others to bottle feed breast milk and if expressing fails some introduce formula milk or solids early to fulfil this ideal. Accounts of prioritising bonding and family emotional well-being are employed to counter any implications that families are not doing the best for the health of their baby by not exclusively breast feeding. A few parents prioritise the ideal of exclusive breast feeding above all other facets of individual or family well-being. A model of 'intensive mothering' has been described where a strong mother-infant bond is fulfilled by exclusive breast feeding on demand and is of paramount importance. ${ }^{44}$ For first-time parents, a mismatch can occur between expectations and the reality of how family, friends and health professionals help them practically and emotionally with feeding, parenting and household tasks. For many, there are barriers to asking for help, with few feeling confident enough to ask and women prefer professionals and others to offer help.

What would make a difference? Opportunities for significant others to be involved in discussions about roles, bonding and coping with breast feeding after birth might help families to adapt and maintain family wellbeing. Proactive offers of help are preferred.

\section{Time values and strategies}

A priority for many new parents is 'getting the baby into a routine', as attaining a regular feeding and sleeping pattern helps to adjust to changes in roles and use of time. First-time parents in particular can find the lack of time for non-baby-related activities and 'me time' a major challenge for which they are not prepared. Even those who have anticipated devoting themselves to feeding may struggle with the time taken to breast feed, feeling anxious to 'get back in control' of their lives. At the other extreme, a few women who fit the 'intense mothering' model willingly sacrifice other activities for their ideal and thrive on fulfilling this role. Priorities for the use of time vary but often focus on restoring pre-pregnancy activities and values, in particular sleep, image (hair, nails, clothes), exercise, friendships, couple or family time including attention to other children and housework. Reconciling these ideals and values with exclusive breast feeding can be challenging. Parents who do reconcile ideals with reality can feel empowered and those who struggle can feel guilty or inadequate as parents in relation to their own ideals or those of others. Return to work can symbolise 'the end for the boob' for some, who introduce formula milk or solids prior to 6 months to facilitate childcare arrangements. The moral work of breast feeding and perceptions of being a good or bad mother have been explored in depth elsewhere. ${ }^{45} 46$

What would make a difference? Women benefit from helpers who understand the tensions between ideals and reality experienced while feeding a baby, who are woman and family centred rather than focused primarily on breast feeding and can build confidence and increase self-efficacy.

\section{Rules and being a 'good' parent}

In family accounts of interactions with health professionals, there is a lack of clarity about the breastfeeding ideals derived from current evidence-based guidance: exclusive breast feeding for 6 months is best; breast feeding for longer than 6 months is ideal and any breast milk is better than none. ${ }^{1}{ }^{19}$ In contrast, accounts of advice about the ideal time to introduce solids were more clearly recalled, but inconsistencies in health professional advice were recounted. Some parents report not always being honest about their feeding behaviour with health professionals if they were not following advice. This reflects the complexity and ambiguity of the feeding messages within current guidance, leading to communication challenges for health professionals. ${ }^{47}$ Dichotomies of 'good' or 'bad', 'right' or 'wrong', 'breast or bottle' prevail in accounts 
of interactions with health professionals, with support for giving both formula and breast milk or self-evaluations on a continuum like doing 'well enough' less common. The emphasis on the technical skills of correct positioning and attachment: 'if it hurts you are doing it wrong' can leave some women feeling a failure, whereas other women distrust this dictum and attribute success to being 'lucky', allowing their self-esteem to be more protected. Rules are recounted where the rationale to parents is unclear: expressing must not begin before 8 or 12 weeks, no nipple creams or shields, bottles and teats confuse the baby and babies must feed within a certain time after birth. Our interpretation is that well-meaning health professionals who wish to promote the ideal of exclusive breast feeding until 6 months convey some advice in a black and white manner, where the supporting research evidence is less clear-cut. ${ }^{48}$ Concern about doing infant feeding 'properly' adds to the pressure on unconfident new parents, with some describing it as 'just one big guilt trip' and feeling 'heartbroken' when a decision to stop breast feeding is made before the woman's ideal time. It is widely acknowledged that health professionals 'have always got to be seen to be saying the right thing'. However, women appreciate communication with professionals that embraces the reality of how difficult it is to attain feeding ideals and is attentive to the emotional consequences of compromising between the different health and family values. Such accounts invariably feature reassurance, confidence building, normalising experiences and time spent developing a trusting relationship.

What would make a difference? Whereas a womancentred communication style can ameliorate parental distress, a breastfeeding-centred or formulaic guideline and rules-based style can increase it. The latter can influence feeding decisions and actions as it can undermine women's confidence, experience and the wider family situation.

\section{Pivotal points and feeding transitions}

When physical, emotional or social difficulties arise in the first 6 months after birth, parents believe that changing the feeding behaviour is one of the few immediate actions within their control that might restore their primary goal of family well-being. Our interpretation is that these pivotal points where feeding behaviour changes represent a conflict between ideals and reality. The trigger for a pivotal point may be somatic, emotional, social, cultural or environmental and examples are well documented in the research literature describing the reasons why women change their feeding behaviour. ${ }^{6}{ }^{10}$ For some in our study, the pivotal points were brief, intense, accompanied by significant emotional distress and feeding behaviour changed promptly. These intense pivotal points mostly occurred with transition from breast feeding to formula in the early weeks when the mother and baby are learning a new skill at the same time as recovering from the physical and emotional consequences of childbirth. They also occurred at crisis times like illness. For others, pivotal points and feeding transitions were a more gradual cognitive process, weighing up the pros and the cons and accompanied by less emotional dissonance. More gradual pivotal points are recounted particularly by parents with older children, those with strong family and social network support and around the introduction of solids. Families provide accounts of timely intervention around pivotal points which enabled them to continue breast feeding or delay the introduction of solids. There are missed opportunities for help, for example, midwife home visits when the baby is asleep or busy ward staff who have other priorities like drug rounds. Distress can increase when care is provided by an unknown person, staff are 'too busy', conflicting advice is encountered or where help is not available. Our analysis suggests that mothers are particularly likely to stop breast feeding or to introduce solids early at a pivotal point if they lack health professional support at an important time, lack a readily available network of family and friends to provide emotional support and practical help or have significant others who formula fed or had negative breastfeeding experiences.

From a new mother's perspective, availability of trusted family, friends or professionals who are able to provide emotional and practical help are perceived as key contributors to advantage or disadvantage with regard to infant feeding. Yet not all help provided is perceived as beneficial to breast feeding, introduction of solids or maternal well-being and it can create tension and a conflict in ideals. Pivotal points are common at around 4 months, if babies change their crying, feeding or sleep behaviours. Even parents who have 'persevered' with their ideals may reach a point when they introduce formula or solids earlier than planned in search of the immediate gain of a more settled contented baby, relief from their anxiety and more sleep. Many parents collect tips and suggestions from a variety of information sources, the media, family and friends, health professionals and try many strategies before introducing formula or solids. Influence depends on the value and trust attached to the source and what fits best with their circumstances.

What would make a difference? Our interpretation is that infant feeding care would improve by providing more proactive rather than reactive care, anticipating mismatches between ideals and reality that underlie pivotal points and providing skilled family-centred help to resolve difficulties.

\section{DISCUSSION}

In this paper, we describe how the philosophical positions of idealism and realism underpin communication within and between families and health professionals about how to feed infants in the first 6 months after birth. Idealism underpins WHO global recommendation of exclusive breast feeding for 6 months and the targets or indicators set by governments in many countries. Six months exclusive breast feeding is considered unrealistic 
and unachievable by many families and promoting this is perceived as setting parents up to fail. Our data were collected prior to widely publicised and contested research questioning the 6-month guideline. ${ }^{48}$ Conflicts between health and non-health ideals and values for parents create tensions, leading to pivotal points whereby parents change their infant feeding behaviour to restore their ultimate goal of family well-being. Discounting future health in favour of immediate gains has been widely described particularly among disadvantaged families. ${ }^{27} 49$ The willpower needed to persevere with feeding ideals may be either harder to engage or more readily depleted for those who are disadvantaged either economically or socially and need their willpower to struggle with other adversities. ${ }^{50}$ An argument can be made for shifting the emphasis from antenatal education to postnatal care, with anticipation and prevention of pivotal points where breast feeding ceases or solids are introduced inappropriately.

The strengths of this study are the serial interviews with women and their significant others, which examine the interactions between individuals and families in health and social contexts. They explored feeding on a continuum, from intentions in pregnancy to how these translated into actions after birth. Unlike many studies, our explicit focus was to ask what would have made or would make a difference to breastfeeding experiences at each interview and to inform future intervention studies. It is uncertain how transferable our data is outside the UK; however, international qualitative evidence synthesis highlights the need for more realistic infant feeding support. ${ }^{10}$ Our study confirms the constructs of intensive mothering, ${ }^{44}$ the give it a go breastfeeding culture, ${ }^{42}$ deviance and the discourses around good and bad mothering, ${ }^{43}{ }^{44}$ the expectation and reality gap, ${ }^{10}$ getting breast feeding 'right', ${ }^{10}$ the medicalisation of breast feeding, ${ }^{9}$ the guilt and failure associated with stopping, ${ }^{10}{ }^{44}$ gaps in health service provision such as prescriptive rather than individualised care, the challenges of breaking the rules, ${ }^{47}$ busy postnatal wards and lack of effective practical and emotional support from health professionals at significant times. ${ }^{9}$ Our sample was more economically advantaged than we had aimed for. Offering incentives to participate in interviews was originally proposed as a strategy to improve recruitment of 'hard to reach' families, but this was not approved by the Ethics Committee. SIMD for postcode of residence seems unreliable for selecting disadvantaged participants particularly in mixed urban and new build areas and for immigrants who are often highly educated but working in low-paid jobs. This is perhaps not surprising as SIMD is not intended for use at an individual level, and age at leaving full-time education is considered the best proxy measure for assessing socioeconomic status. ${ }^{51}$ For infant feeding, it is debatable how valid it is to assess 'advantage' and 'disadvantage' for new parents based on traditional socio-demographic characteristics alone. Not having an emotional and practical support network or being surrounded by significant others who have formula fed, had negative breastfeeding experiences, introduced solids early, are unaware that recommendations have changed are also disadvantages which can influence feeding decisions and health inequalities.

WHO guidance of exclusive breast feeding for 6 months $^{1}$ is intended to inform international government policies, yet it is being widely communicated in written and verbal health service information as an individual feeding goal for parents. Similarly, the pass - fail nature of the BFI accreditation scheme ${ }^{30}$ may generate a 'right-wrong' culture which does not facilitate mothers and health professionals to work in partnership to make individual choices informed by personal values and circumstances. By promoting 6 months exclusive breast feeding, policy makers are encouraging idealistic expectations and goals in pregnancy, but health services are not providing the skilled help required to establish breast feeding after birth. This mismatch between idealism and realism is likely to be a mechanism behind the media stories of mothers feeling pressurised to breast feed. ${ }^{52}$ The theory on changing and sustaining healthy lifestyle behaviours indicates that achievable goals set by individuals themselves, which are mastered and then reset incrementally, known as smart goal setting is effective and builds selfefficacy. ${ }^{53}$ Would changing the message to 'breast feed for as long as you can' and 'introduce solids as close to 6 months as possible' with more individually tailored goal setting, social support and feedback make a difference to breastfeeding outcomes? Or do we just need to rebalance the health service input to increase the intensity and frequency of support after birth around the pivotal points for ceasing to breast feed and introducing solids, as indicated by the evidence for weight management and exercise to prevent disease ${ }^{54}$

The serial narrative interviews employed in this study with open questions and continuity focusing solely on infant feeding are a tool which could be modified for use in clinical encounters to anticipate families most at risk of pivotal points when feeding behaviour changes. We hypothesise that this would assist in the identification of women who are more likely to experience intense pivotal points in the early days with breast feeding or at around 3-4 months with the introduction of solids and facilitate discussion about any potential or actual mismatch between ideals and reality. The dominant discourse in health service policy, research and practice is 'breastfeeding support for women'. Support is an ambiguous word that can infer either a realistic woman centred or a more idealistic breastfeeding-centred philosophy. We advocate that this should change to 'family-centred feeding care' in health service written and oral discourses. The word 'care' has an implicit personcentred meaning and is less likely to be misconstrued as pressurising; 'feeding' embraces solids as well as milk and 'family' acknowledges the important role of others in infant care. Realistic information with a facilitative 
patient-centred style ${ }^{11}$ should aim to minimise tension and distress and help parents feel more confident, with avoidance of 'do-don't' discourses. More acknowledgement of the importance of emotional well-being as an outcome that matters to families is needed. Physiologically, this is explained by the association between stress-reducing oxytocin levels and milk flow. $^{55}$ Emotional well-being is most precarious soon after birth and to address this, the emphasis for professional breastfeeding care should be after rather than before birth. The findings of this study lead us to suggest that it is time to revisit the current ideal of training all health professionals to provide infant feeding care, particularly with shorter hospital stays, reduced routine postnatal contact with families and staff shortages. Certainly, more of the same approach to promoting and supporting breast feeding would seem unlikely to be effective $^{25}$ and service reorganisation will be needed if care is to anticipate pivotal points.

Almost 2 decades ago, there was a debate around idealism in health promotion which questioned the transformation of health into a political value. ${ }^{56} \mathrm{We}$ would argue that it is time to revisit this debate for infant feeding, if we are to design and deliver successful interventions to improve infant feeding outcomes and subsequent health outcomes of future generations. This study is hypothesis generating, and several potential changes to policy and practice could arise from the study messages. Increasing feeding care after birth, proactive rather than reactive care, specialisation with dedicated feeding teams, a family-centred narrative approach rather than checklists, these changes in health service behaviour would all have considerable implications for health professional training, accreditation schemes and resources. Achieving health service change is likely to be just as challenging as achieving patient behaviour change. We would argue that infant feeding is too important and resources too scarce to make changes without robust evidence from randomised controlled trials or other appropriate evaluation strategies.

Acknowledgements We would like to thank all the women, families, NHS staff and colleagues who contributed to this study, Lorna McKee for commenting on this paper and Anne Harrison for assisting with transcription.

Contributors All authors were involved in the design of the study, the analysis of data and the writing and editing of this paper. LC and JB conducted the interviews with participants. All authors had full access to all the data in the study and can take responsibility for the integrity of the data and the accuracy of the data analysis. PH wrote the first draft of the paper, and all authors made important intellectual contributions to the content and approved the final version.

Funding This study was funded by NHS Health Scotland. The Health Service Research Unit, University of Aberdeen, is supported by the Chief Scientist Office (CSO) of the Scottish Government Health Directorates. The views expressed are those of the authors and the authors are all independent of the funding body.

Competing interests None.

Ethics approval Approval was obtained from the North of Scotland Research Ethics Committee (reference number 09/S0802/65). All participants provided written informed consent and any details that could allow identification of participants have been changed to protect confidentiality.

Provenance and peer review Not commissioned; externally peer reviewed.

Data sharing statement A full study report is available at http://www. healthscotland.com/documents/4720.aspx and no additional data are available as consent was not obtained.

\section{REFERENCES}

1. World Health Organization. Global Strategy for Infant and Young Child Feeding. 2003. http://www.who.int/nut/documents/ gs_infant_feeding_text_eng.pdf

2. Centers for Disease Control and Prevention. Breastfeeding. USA. 2011. http://www.cdc.gov/breastfeeding/index.htm

3. Health Canada. Trends in Breastfeeding Practices in Canada (20012008). http://www.hc-sc.gc.ca/fn-an/surveill/nutrition/commun/ prenatal/trends-tendances-eng.php

4. Infant Feeding Survey 2010: Early Results. The Information Centre, Government Statistical Service. 2011. http://www.ic.nhs.uk/statisticsand-data-collections/health-and-lifestyles-related-surveys/infantfeeding-survey/infant-feeding-survey-2010-early-results

5. Infant Feeding Data Sources. Information and Statistics Division. Edinburgh: NHS Scotland, 2010. http://www.isdscotlandarchive.scot. nhs.uk/isd/1764.html

6. Bolling K, Grant K, Hamlyn B, et al. Infant Feeding Survey 2005. UK The Information Centre, Government Statistical Service, 2007.

7. Hector DJ. Complexities and subtleties in the measurement and reporting of breastfeeding practices. Int Breastfeeding J 2011;6:5. http://www.internationalbreastfeedingjournal.com/content/6/1/5

8. Healthy People 2020: Breastfeeding Objectives. USA. 2011. http:// www.usbreastfeeding.org/LegislationPolicy/FederalPolicies/ HealthyPeople2020BreastfeedingObjectives/tabid/120/Default.aspx

9. Mclnnes RJ, Chambers JA. Supporting breastfeeding mothers: qualitative synthesis. J Adv Nurs 2008;62:407-27.

10. Burns E, Schmied V, Sheehan A, et al. A meta-ethnographic synthesis of women's experience of breastfeeding. Matern Child Nutr 2010;6:201-19.

11. Schmied V, Beake S, Sheehan A, et al. Women's perceptions and experiences of breastfeeding support: a metasynthesis. Birth 2011;38:49-60

12. Bhavnani V, Newburn M. Left to Your Own Devices: The Postnatal Care Experiences of 1260 First-Time Mothers. London: National Childbirth Trust, 2010. http://www.nct.org.uk/sites/default/files/ related documents/PostnatalCareSurveyReport5.pdf

13. Department of Health. Breastfeeding and the NHS Priorities and Planning Framework 2003-2006. http://www.dh.gov.uk/en/ Policyandguidance/Healthandsocialcaretopics/ Maternalandinfantnutrition/DH_4071692

14. Department of Health. Operational Plans 2008/9-2010/11: National Planning Guidance and "Vital Signs". 2011. http://www.dh.gov.uk/en/ Publicationsandstatistics/Publications/PublicationsPolicyAnd Guidance/DH 082542

15. The Scottish Government. Healthy Eating, Active Living: An Action Plan to Improve Diet, Increase Physical Activity and Tackle Obesity. http://www.scotland.gov.uk/Resource/Doc/228860/ 0061963.pdf

16. Cattaneo A, Borgnolo G, Simon G. Breastfeeding by objectives. Eur J Public Health 2001;11:397-401.

17. Cattaneo A, Giuliani C. Breastfeeding in Friuli Venezia Giulia. Eur J Public Health 2006;16:111.

18. The Scottish Government. CEL 36: Nutrition of Women of Childbearing Age, Pregnant Women and Children Under Five in Disadvantaged Areas-Funding Allocation 2008-2011. http://www. scotland.gov.uk/Publications/2008/06/20155902/5.

19. National Institute for Health and Clinical Excellence. Improving the Nutrition of Pregnant and Breastfeeding Mothers and Children in Low Income Households. 2008. http://guidance.nice.org.uk/PH11

20. Fair Society, Healthy Lives: The Marmot Review. Strategic Review of Health Inequalities in England Post. 2010. http://www.marmotreview. org/

21. Canning D, Bowser D. Investing in health to improve the wellbeing of the disadvantaged: reversing the argument of Fair Society, healthy Lives (The Marmot Review). Soc Sci Med 2010;71:1223-6; discussion 1254-8.

22. National Institute for Health and Clinical Excellence. Postnatal Care Routine Postnatal Care of Women and Their Babies. 2008. http:// www.nice.org.uk/CG037

23. Chung M, Raman G, Trikalinos $\mathrm{T}$, et al. Interventions in primary care to promote breastfeeding: an evidence review for the U.S. Preventive Services Task Force. Ann Intern Med 2008;149:565-82. 
24. Britton C, McCormick FM, Renfrew MJ, et al. Support for breastfeeding mothers. Cochrane Database Syst Rev 2007;(1): CD002869.

25. Hoddinott $P$, Seyara R, Marais D. Global evidence synthesis and UK idiosyncrasy: why have recent UK trials had no significant effects on breastfeeding rates? Matern Child Nutr 2011;7:221-7.

26. Spiby $\mathrm{H}, \mathrm{McC}$ cormick $\mathrm{F}$, Wallace $\mathrm{L}$, et al. A systematic review of education and evidence-based practice interventions with health professionals and breast feeding counsellors on duration of breast feeding. Midwifery 2009;25:50-61.

27. Asthana S, Halliday J. Developing an evidence base for policies and interventions to address health inequalities: the analysis of public health regimes. Milbank Q 2006;84:577-603.

28. Strack F, Deutsch R. Reflective and impulsive determinants of social behavior. Pers Soc Psychol Rev 2004;8:220.

29. Hoddinott P, Pill R. Qualitative study of decisions about infant feeding among women in east end of London. BMJ 1999;318:30-4.

30. UNICEF. Baby Friendly Initiative. 2007. http://www.babyfriendly.org.uk

31. Kramer MS, Chalmers B, Hodnett ED, et al. Promotion of Breastfeeding Intervention Trial (PROBIT): a randomized trial in the Republic of Belarus. JAMA 2001;285:413-20.

32. Bartington S, Griffiths LJ, Tate AR, et al; The Millennium Cohort Study Child Health Group. Are breastfeeding rates higher among mothers delivering in baby friendly accredited maternity units in the UK? Int J Epidemiol 2006;35:1178-86.

33. Craig P, Dieppe P, Macintyre S, et al. Developing and Evaluating Complex Interventions: New Guidance. London: Medical Research Council, 2008.

34. Murray SA, Kendall M, Carduff E, et al. Use of serial qualitative interviews to understand patients' evolving experiences and needs. BMJ 2009;339:b3702.

35. McLeroy KR, Bibeau D, Steckler A, et al. An ecological perspective on health promotion programs. Health Educ Q 1988;15:351-77.

36. World Health Organization. Indicators Assessing Infant Young Child Feeding Practices. 2008. http://www.who.int/child_adolescent_ health/documents/9789241596664/en/index.html

37. Scottish Government. Scottish Index of Multiple Deprivation. 2009. http://www.scotland.gov.uk/Topics/Statistics/SIMD/ SIMDPostcodeLookup

38. Hoddinott P, Craig L, Britten J, et al. A Prospective Study Exploring The Early Infant Feeding Experiences of Parents and Their Significant Others During the First 6 Months of Life: What Would Make A Difference? Edinburgh: NHS Health Scotland, 2010. http:// www.healthscotland.com/documents/4720.aspx
39. National Centre for Social Research. Framework Software. http:// www.framework-natcen.co.uk/

40. Ritchie J, Lewis J. Qualitative Research Practice. London: Sage, 2003.

41. Protection, Promotion and Support of Breastfeeding in Europe: $A$ Blueprint For Action (Revised 2008). http://www.iblce-europe.org/ Download/Blueprint/Blueprint\%20English.pdf

42. Bailey C, Pain RH, Aarvold JE. A 'give it a go' breast-feeding culture and early cessation among low-income mothers. Midwifery 2004;20:240-50.

43. Murphy E. "Breast is best": infant feeding decisions and maternal deviance. Sociol Health IIIness 1999;21:187-208.

44. Lee EJ. Living with risk in the age of intensive motherhood: maternal identity and infant feeding. Health Risk Soc 2008;10:467-77.

45. Ryan K, Bissell $P$, Alexander J. Moral work in women's narratives of breastfeeding. Soc Sci Med 2010;70:951-8.

46. Marshall JL, Godfrey M, Renfrew M. Being a 'good mother': managing breastfeeding and merging identities. Soc Sci Med 2007;65:2147-59.

47. Furber CM, Thomson AM. 'Breaking the rules' in baby-feeding practice in the UK: deviance and good practice? Midwifery 2006;22:365-76.

48. Fewtrell $\mathrm{M}$, Wilson DC, Booth $\mathrm{I}$, et al. Six months of exclusive breast feeding: how good is the evidence? BMJ 2011;342:c5955.

49. Tice DM. Emotional distress regulation takes precedence over impulse control: if you feel bad, do it! J Pers Soc Psychol 2001;80:53

50. Baumeister RF, Bratslavsky E, Muraven M, et al. Ego depletion: is the active self a limited resource? J Pers Soc Psychol 1998;74:1252-65.

51. Marmot M. Status Syndrome. London: Bloomsbury Publishing Plc, 2004.

52. Groskop V. Let The Breastfeeding Rebellion Begin. London, UK: Guardian, 2009

53. National Institute for Health and Clinical Excellence. Behavioura Change at Population, Community and Individual Levels. London: National Institute for Health and Clinical Excellence, 2007.

54. Greaves C, Sheppard K, Abraham C, et al. Systematic review of reviews of intervention components associated with increased effectiveness in dietary and physical activity interventions. BMC Public Health 2011;11:119.

55. Riordan J, Wambach K. Breastfeeding and Human Lactation. 4th edn. Sudbury, USA: Jones and Bartlett, 2010.

56. Kelly MP, Charlton B. Health promotion: time for a new philosophy? Br J Gen Pract 1992;42:223. 


\section{Correction}

Hoddinott P, Craig LCA, Britten J, et al. A serial qualitative interview study of infant feeding experiences: idealism meets realism. BMJ Open 2012;2:e000504. The last author's middle initial was published incorrectly. The correct author name is Rhona J McInnes.

BMJ Open 2012;2:e000504corr1. doi:10.1136/bmjopen-2012-000504corr1 